\title{
Fertirrigação potássica na cultura do morango no litoral Cearense
}

\author{
Geocleber Gomes de Sousa (1); Thales Vinicus de Araújo Viana ('); Ednângelo Duarte Pereira (²); \\ André Henrique Pinheiro Albuquerque $\left({ }^{1 *}\right)$; Albanise Barbosa Marinho $\left({ }^{2}\right)$; Benito Moreira de Azevedo $\left({ }^{1}\right)$ \\ (') Universidade Federal do Ceará (UFC), Departamento de Engenharia Agrícola, Av. Mister Hull, s/n, 60356-000 Fortaleza (CE), Brasil. \\ (2) Universidade da Integração Internacional da Lusofonia Afro-Brasileira (UNILAB), Av. da Abolição, 3, 62790-000 Redenção (CE), \\ Brasil. \\ (*) Autor correspondente: andrehenrique84@yahoo.com.br
}

Recebido: 29/nov./2013; Aceito: 20/jan./2014

\begin{abstract}
Resumo
Objetivou-se avaliar efeitos de doses de potássio aplicadas via fertirrigação no acúmulo de biomassa e desempenho produtivo de cultivares de morangueiro no litoral cearense. O experimento foi conduzido a pleno sol, no período de abril a agosto de 2012, em Fortaleza, Ceará. Os tratamentos foram distribuídos em blocos ao acaso, em esquema fatorial $5 \times 2$, referente a cinco doses de potássio (0,65 g; 0,97 g; 1,29 g; 1,61 g e 1,93 g por planta, semanalmente) aplicadas via fertirrigação e duas cultivares de morangueiro (Oso grande e Verão), em cinco repetições. Aos 40 dias após o transplantio iniciou-se a colheita dos frutos, que foram avaliados semanalmente quanto ao seu número por planta, ao diâmetro, ao comprimento, ao peso médio e à produtividade. A adubação potássica estimula a produção de matéria seca da parte aérea e da raiz para as cultivares de morango Oso grande e Verão. A dose de potássio 0,65 g por planta foi a mais eficiente para o número de frutos por planta para a cultivar Oso grande e para o peso médio de fruto com a Verão. O aumento da concentração de potássio reduz a produtividade das cultivares de morango Oso grande e Verão. A cultivar Oso grande apresenta maior adaptabilidade às condições climáticas do litoral cearense do que a Verão.
\end{abstract}

Palavras-chave: Fragaria $x$ ananassa Duch, adubação, produtividade.

\section{Potassium fertirrigation of strawberry crop in Ceará}

\begin{abstract}
This study was aimed at evaluating the effects of potassium doses applied by fertigation on biomass accumulation and yield performance of strawberry cultivars in the Ceará coast. The experiment was conducted in full sunlight, in the interval from April to August 2012, in Fortaleza, Ceará. Treatments were disposed in a randomized blocks design, in a $2 \times 5$ factorial arrangement, consisting of five potassium doses $(0.65,0.97,1.29,1.61$ and 1.93 g plant per week) and two strawberry cultivars (Oso Grande and Verão), with five replicates. At the 40th day after transplanting, the fruit harvesting started. The fruits were evaluated weekly, relatively to the the number of fruits per plant, fruit diameter, fruit length, average fruit weight and, at the end of the harvest period, the total yield. Potassium fertilization stimulates the production of dry matter of shoot and root for strawberry cultivars Oso grande and Verão. A potassium dose of 0.65 g plant $^{-1}$ was the most efficient potassium dose (for fruit number per plant) for the Oso Grande cultivar and (for the average fruit weight) for the Verão cultivar. Increased potassium concentration reduces the yield of strawberry cultivars Oso grande and Verão. The Oso grande cultivar has higher adaptability to climatic conditions of Ceará than Verão.
\end{abstract}

Key words: Fragaria x ananassa Duch, fertilization, yield.

\section{INTRODUÇÃO}

O morangueiro (Fragaria $x$ ananassa Duch.) pertence à família das Rosaceas e é produzido e apreciado nas mais variadas regióes do mundo, sendo a espécie do grupo das pequenas frutas de maior expressão econômica (Oliveira et al., 2006). Apesar de ser típico de países frios, o morangueiro adapta-se amplamente às mais diversas condiçôes climáticas, graças à grande diversidade genética, que conta com inúmeras variedades e híbridos em todo o mundo (Padovani, 1991).

A cultura do morangueiro possui ampla distribuiçáo geográfica em virtude de sua alta capacidade de adaptação às condiçóes de cultivo e de clima (Morales et al., 2012). É uma cultura com alta produtividade e, portanto, com retorno econômico para o produtor; são vários os métodos 
de cultivo desenvolvidos, que interfem na produtividade e na qualidade dos frutos colhidos (Andriolo et al., 2009).

Uma alternativa viável para reduzirem-se essas perdas e melhorar a qualidade do produto está no uso da adubação potássica. O potássio participa no metabolismo de carboidratos, influenciando diretamente na produtividade, $\mathrm{e}$ mantém a turgescência da folha, razão pela qual é essencial no transporte interno de açúcares e no equilíbrio eletroquímico da planta (Andriolo et al., 2010).

Prado (2008) afirma que o K é importante para a formação de carboidratos das folhas e tem papel fundamental na translocação desses assimilados para as diversas partes da planta, principalmente os frutos. Já o excesso de potássio pode inibir a absorçẫo de $\mathrm{Ca}^{2+} \mathrm{e} \mathrm{Mg}^{2+}$, chegando muitas vezes a causar deficiência desses dois nutrientes. Esse excesso tende a induzir alteraçóes no peso do fruto e, consequentemente, efeitos depressivos na produtividade e na qualidade de frutos (Andriolo et al., 2010; Barroso et al., 2011).

Cabe ressaltar que o Ké o nutriente que mais favorece a qualidade do morango, aumenta os teores de sólidos solúveis totais e de ácido ascórbico, além de melhorar o aroma, o sabor, a cor e a firmeza das frutas. Além disso, confere maior longevidade à planta, tornando-a mais produtiva por um período de tempo maior (Pacheco et al., 2007). Nesse contexto, a hipótese do trabalho é que a adubação potássica pode maximizar o acúmulo de biomassa e a produtividade de cultivares de morangueiro, mesmo sob temperaturas elevadas.

Em consequência, o objetivo deste trabalho foi avaliar efeitos de doses de potássio no acúmulo de biomassa e desempenho produtivo de cultivares de morangueiro no litoral cearense.

\section{MATERIAL E MÉTODOS}

O experimento foi conduzido na área experimental da Estaçáo Agrometeorológica do Departamento de Engenharia Agrícola do Centro de Ciências Agrárias da Universidade

Tabela 1. Valores médios mensais das variáveis temperatura, umidade relativa e velocidade do vento e totalização mensal da precipitação durante a condução do experimento

\begin{tabular}{ccccc} 
Mês & $\begin{array}{c}\text { Temperatura } \\
\text { média do ar } \\
\left({ }^{\circ} \mathbf{C}\right)\end{array}$ & $\begin{array}{c}\text { Umidade } \\
\text { relativa } \\
(\%)\end{array}$ & $\begin{array}{c}\text { Velocidade } \\
\text { do vento } \\
\left(\mathbf{m}^{-1} \mathbf{s}^{-1}\right.\end{array}$ & $\begin{array}{c}\text { Precipitação } \\
(\mathbf{m m})\end{array}$ \\
\hline Abril & 26,2 & 84 & 2,5 & 359,7 \\
\hline Maio & 26,8 & 80 & 2,4 & 226,3 \\
\hline Junho & 26,7 & 77 & 3,2 & 128,8 \\
\hline Julho & 26,4 & 75 & 2,9 & 129,7 \\
\hline Agosto & 26,6 & 71 & 3,7 & 49 \\
\hline
\end{tabular}

Fonte: Estaçăo Agrometeorológica da Universidade Federal do Ceará (UFC)
Federal do Ceará (UFC), no município de Fortaleza, Ceará, coordenadas geográficas $03^{\circ} 45^{\prime} \mathrm{S}, 38^{\circ} 33^{\prime} \mathrm{W}$. O clima da regiâo, segundo a classificação de Koeppen, é do tipo Aw', tropical chuvoso, com temperaturas elevadas e com estação chuvosa predominante no outono.

Os valores médios mensais das variáveis climáticas durante a condução do experimento, entre abril e agosto de 2012, encontram-se na tabela 1.

As características físicas e químicas do substrato utilizado (composto por solo + esterco + areia), antes da aplicação dos tratamentos, estáo apresentadas na tabela 2, conforme EMBRAPA (1997).

A cultura utilizada foi o morangueiro (Fragaria $x$ ananassa Duch), sendo que o transplantio das mudas foi realizado em abril de 2012, tendo sido postas duas plantas por vaso, com volume de $35 \mathrm{~L}$, contendo o substrato preparado. Após o estabelecimento das mudas, aos oito dias após o transplantio (DAT) iniciaram-se as aplicaçôes dos tratamentos.

O delineamento experimental utilizado foi em blocos casualizados, em esquema fatorial $5 \times 2$, referente a cinco doses de potássio $(0,0 \mathrm{~g} ; 2,0 \mathrm{~g} ; 3,0 \mathrm{~g} ; 4,0 \mathrm{~g}$ e $5,0 \mathrm{~g}$ por planta) e duas cultivares de morangueiro (Oso grande e Verão), em cinco repetiçôes.

A adubação das plantas do morango foi baseada na análise do substrato e consistiu basicamente na aplicação de $18 \mathrm{~g}$ por planta de ureia, $30 \mathrm{~g}$ por planta de superfosfato simples e $10 \mathrm{~g}$ por planta de cloreto de potássio, correspondentes às doses de $180 \mathrm{~kg}, 300 \mathrm{~kg}$ e $100 \mathrm{~kg} \mathrm{ha}^{-1}$ de $\mathrm{N}, \mathrm{P}_{2} \mathrm{O}_{5} \mathrm{e}$ $\mathrm{K}_{2} \mathrm{O}$, respectivamente, de acordo com Raij et al. (1996). As adubaçôes com $\mathrm{K}_{2} \mathrm{O}$ foram aplicadas por fertirrigaçáo, com intervalo de sete dias, no ciclo da cultura, feita de acordo com a recomendação de Raij et al. (1996).

As doses de potássio foram definidas com base em informaçóes de produtor da regiáo da Serra da Ibiapaba, Ceará, ou seja, a dose considerada testemunha foi de $1,29 \mathrm{~g}$ de $\mathrm{K}_{2} \mathrm{O}$ por planta (o que representa $100 \%$ da dose recomendada). Já as demais doses, 0,65 g, 0,97 g, 1,61 g e 1,93 g de $\mathrm{K}_{2} \mathrm{O}$ por planta, representando $50 \%, 75 \%, 125 \%$ e $150 \%$ da dose recomendada, foram aplicadas durante o experimento.

A irrigação das plantas foi realizada diariamente através de lâmina de irrigaçáo uniforme para todos os tratamentos, com base na evaporação medida em um tanque classe $\mathrm{A}$, por meio de emissores com vazão de $4 \mathrm{~L} \mathrm{~h}^{-1}$ a uma pressão de $1 \mathrm{kgf} \mathrm{cm}{ }^{-2}$. O sistema de irrigaçáo utilizado foi localizado, tipo gotejamento. $\mathrm{O}$ conjunto motobomba trabalhou de forma submersa em um poço profundo, próximo à área do experimento.

Para atenuar a temperatura do ar foi utilizado um sistema de nebulizaçáo acionado por um timer. Realizaram-se diariamente dez nebulizaçóes de dois minutos de duração com

Tabela 2. Resultado das análises química e física do substrato utilizado no morangueiro antes da aplicação dos tratamentos

\begin{tabular}{|c|c|c|c|c|c|c|c|c|c|c|}
\hline CT & $\begin{array}{c}\text { DS } \\
\mathrm{kg} \cdot \mathrm{dm}^{-3}\end{array}$ & $\mathrm{Ca}$ & Mg & $\begin{array}{c}\mathrm{Na} \\
\text { mmolc.dm }{ }^{-3}\end{array}$ & $\mathrm{H}+\mathrm{Al}$ & Al & $\begin{array}{c}\mathrm{K} \\
\mathrm{mg} \cdot \mathrm{dm}^{-3}\end{array}$ & $\begin{array}{c}\text { PST } \\
\%\end{array}$ & $\mathrm{pH}$ & $\begin{array}{l}\text { CEes } \\
\text { dS. } m^{-1}\end{array}$ \\
\hline Areia & 1,41 & 26,3 & 25,6 & 45 & 19 & ND & 0,058 & 36 & 6,9 & 7,8 \\
\hline
\end{tabular}

CT = classe textural; DS = densidade do solo; CEes = Condutividade elétrica do extrato de saturação; PST = percentagem de sódio trocável 
água com condutividade elétrica de $0,8 \mathrm{dS} \mathrm{m}^{-1}$, distribuídas no período das 09:20 às 14:40 h.

O período de colheita estendeu-se de maio a agosto de 2012, sendo realizada uma vez por semana, totalizando 15 avaliaçóes. Em cada uma foram determinados o comprimento, o diâmetro, o número e o peso dos frutos e, no final ciclo, a produtividade por planta. $\mathrm{O}$ estádio de maturação dos frutos para a colheita foi de 3/4 maduros ou com a superfície vermelho-intensa, conforme realizado por Camargo et al. (2009).

Após a última avaliação, as plantas foram colhidas e separadas em folhas + caule e em raiz. Em seguida foram acondicionadas em sacos de papel identificados e colocadas para secar em estufa a $60^{\circ} \mathrm{C}$, até atingirem valor constante de matéria seca. As variáveis estudadas foram matéria seca da parte aérea, matéria seca da raiz e matéria seca total.

Os resultados foram submetidos à análise de variância e de regressão e as médias comparadas pelo teste de Tukey com $\mathrm{P}<0,05$, utilizando-se o programa ASSISTAT. 7.6 Beta. $\mathrm{Na}$ análise de regressão, as equaçôes de regressão que melhor se ajustaram aos dados foram escolhidas com base na significância dos coeficientes de regressão ao nível de significância de $1 \%\left({ }^{* *}\right)$ e $5 \%\left(^{*}\right)$ pelo teste $F$, e no maior coeficiente de determinação $\left(\mathrm{R}^{2}\right)$.

\section{RESULTADOS E DISCUSSÃO}

Para as variáveis de produção de matéria seca não se verificou efeito significativo da interação doses de $\mathrm{K}$ versus cultivares de morangueiro (Tabela 3). No entanto, houve efeito significativo das cultivares para a matéria seca da parte aérea e das diferentes doses de potássio para a matéria seca da raiz total.

A partir do teste de comparação de médias observa-se que a cultivar Oso grande apresentou desempenho superior

Tabela 3. Resumo da análise de variância para as variáveis matéria seca da parte aérea (MSPA), matéria seca da raiz (MSR) e matéria seca total (MST) em função de diferentes doses de potássio sobre duas cultivares de morangueiro

\begin{tabular}{|ccccc|}
\hline FV & GL & \multicolumn{3}{c|}{ Quadrado médio } \\
\hline Doses (D) & 4 & $105,17^{\text {ns }}$ & $82^{*}$ & $356,02^{* *}$ \\
\hline Cultivares (C) & 1 & $292,82^{* *}$ & $36,98^{\text {ns }}$ & $537,92^{* *}$ \\
\hline DxC & 4 & $181,47^{\text {ns }}$ & $29,58^{\text {ns }}$ & $73,12^{\text {ns }}$ \\
\hline Tratamentos & 9 & 159,83 & 53,7 & 250,49 \\
\hline Resíduo & 40 & 71,16 & 16,38 & 88,85 \\
\hline Total & 49 & - & - & - \\
\hline CV & - & 16,42 & 17,52 & 12,66 \\
\hline MG & - & 51,38 & 23,1 & 74,48 \\
\hline
\end{tabular}

$\mathrm{FV}=$ fonte de variaçăo; $\mathrm{CV}=$ coeficiente de variaçăo; $\mathrm{MG}=$ média geral; $\mathrm{GL}=$ grau de liberdade; ns = năo significativo; ${ }^{*}$ significativo pelo teste $F$ a $5 \%$; ${ }^{*}$ significativo pelo teste $F$ a $1 \%$ quanto à produçáo de matéria seca da parte aérea, em relaçáo à cultivar Verão (Figura 1), revelando maior adaptação dessa cultivar às condiçôes edafoclimáticas do litoral cearense.

Em seu trabalho, Calvete et al. (2012) alertam que em temperaturas extremamente altas ocorrem desnaturação de proteínas, desorganizaçáo de parede celular e alterações de processos bioquímicos. Esses pesquisadores lembram ainda que quando a umidade relativa do ar cai durante o dia, as plantas transpiram e respiram demais, consumindo a própria energia produzida pelo processo de fotossíntese e reduzindo a disponibilização de fotoassimilados para uso nos processos de crescimento. Essa alteração que pode ser minimizada com o uso de cultivar mais adaptada a essas condiçóes adversas.

Francescangeli et al. (2006) concluíram que o maior crescimento vegetativo de plantas de morango está associado a taxas de crescimento mais elevadas da área foliar da cultura, a qual aumenta a quantidade de assimilados produzidos e estocados, melhorando assim a área fotossintética, como reportam os resultados de Taiz e Zeiger (2009).

Verifica-se na figura 2, que as doses crescentes de potássio aumentaram de forma linear a matéria seca da raiz para a cultivar Oso grande, revelando um valor máximo de 25,6 g por planta na maior dosagem de $\mathrm{K}_{2} \mathrm{O}$, enquanto, para a cultivar Verão, o modelo que melhor se ajustou aos dados foi o polinomial quadrático, com uma MSR máxima de 20,29 g para uma dose de $\mathrm{K}$ de 2,87 g por planta.

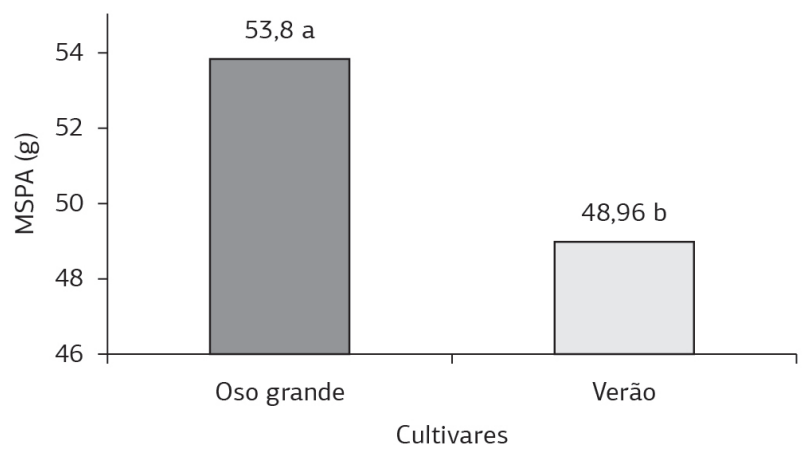

Figura 1. Matéria seca da parte aérea de plantas do morangueiro em funçáo das doses de potássio para as cultivares Oso grande e Verão.

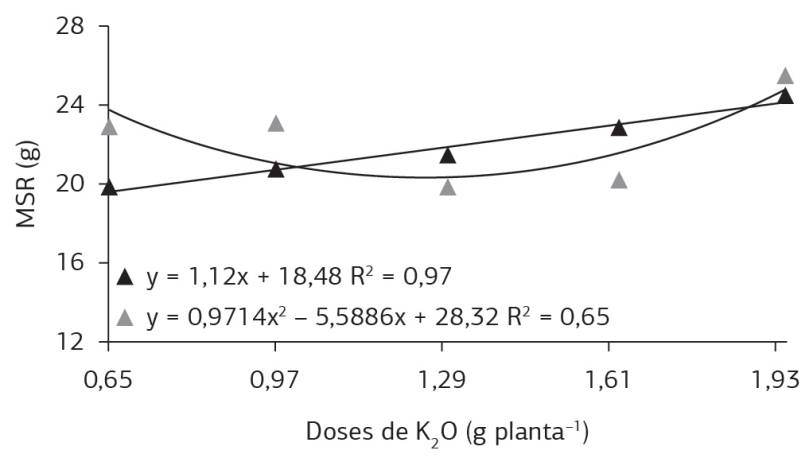

Figura 2. Matéria seca da raiz de plantas do morangueiro em função das doses de potássio para as cultivares Oso grande $(\boldsymbol{\Lambda})$ e Verão $(\boldsymbol{\Lambda})$. 
Esse comportamento positivo da adubação potássica reflete-se na afirmaçáo de Prado (2008), pois a deficiência de potássio ocasiona redução na atividade fotossintética das folhas, aumento da respiração radicular, redução no crescimento dos brotos e aumento no crescimento radicular (Epstein e Bloom, 2006).

Comportamento oposto ao desse estudo foi evidenciado por Marques et al. (2011) na avaliação da adubação potássica em outra hortaliça (berinjela), constatando com o aumento da concentração de $\mathrm{K}_{2} \mathrm{O}$ uma redução na massa seca da raiz. Esses autores alertam que principalmente $\mathrm{Na}^{+} \mathrm{e} \mathrm{Cl}^{-}$podem causar o desequilíbrio na homeostase do potencial de água e o desbalanço iônico na interface solo-planta e promover toxicidade no vegetal, afetando o seu crescimento e a produção de fitomassa.

Como verificado para a matéria seca da parte aérea, a matéria seca total das plantas de morangueiro da cultivar Oso grande também foi superior à das plantas da cultivar Veráo (Figura 3). O modelo que melhor se ajustou aos dados para ambas as cultivares foi o polinomial quadrático. Por esse modelo, as plantas iriam produzir uma MST máxima por planta de 83,94 g com a dose estimada em 3,25 g de $\mathrm{K}_{2} \mathrm{O}$ para a cultivar Oso grande e de $77,12 \mathrm{~g}$ com a dose estimada em 4,37 $\mathrm{g}$ de $\mathrm{K}_{2} \mathrm{O}$ para a cultivar Verão.

Essa situação está em conformidade com Epstein e Bloom (2006), que relataram que as adubaçóes potássicas

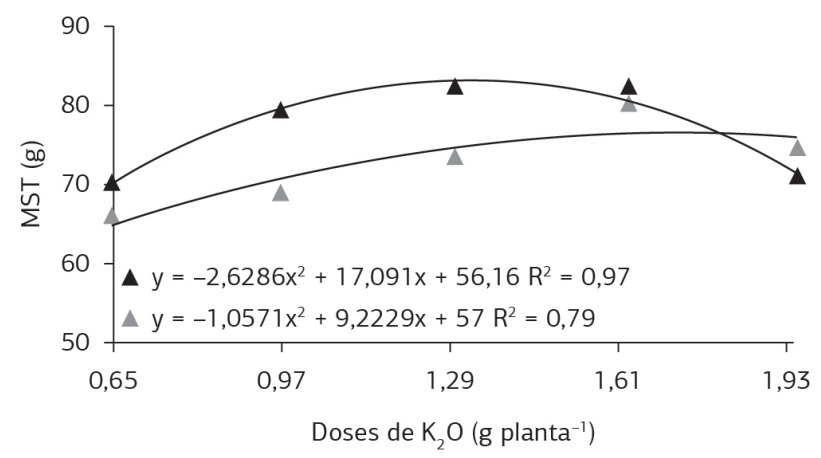

Figura 3. Matéria seca total de plantas do morangueiro em função das doses de potássio para as cultivares Oso grande $(\boldsymbol{\Lambda})$ e Verão $(\boldsymbol{\Lambda})$. são importantes porque não só interferem no crescimento vegetativo mas também no rendimento e na qualidade do produto colhido. Outro aspecto que pode ter influenciado as respostas isoladas das doses de $\mathrm{K}_{2} \mathrm{O}$ sobre o desempenho da biomassa total da cultura do morangueiro pode estar na eficiência de absorçáo desse nutriente pela planta (Andriolo et al., 2010).

Importante destacar que apesar da adição da adubação potássica ao substrato contribuir para o melhor desenvolvimento da planta, doses excessivas podem comprometer o comportamento vegetativo das plantas, inclusive do morangueiro (Andriolo et al., 2009). O excesso desse nutriente pode causar desequilíbrio nos níveis de cálcio (Ca) e magnésio $(\mathrm{Mg})$, afetando o crescimento de órgãos e partes mais jovens como gemas (meristemas) e pontas de raízes. Provavelmente, a redução da MST na maior dosagem deve ser consequência desse antagonismo entre esses elementos minerais.

$\mathrm{Na}$ análise de variância (Tabela 4), observa-se que as interaçóes entre as diferentes doses de potássio versus cultivares de morango não afetaram significativamente as variáveis comprimento de fruto $(\mathrm{CF})$, diâmetro de fruto (DF), número de frutos (NF) e produtividade (PROD) em nível de significância de 1 e $5 \%$ pelo teste $F$. O peso de fruto, por sua vez, foi significativamente influenciado pelos fatores estudados. Já o número de frutos e a produtividade foram influenciados pelas diferentes doses de $\mathrm{K}_{2} \mathrm{O}$.

De acordo com a figura 4, a cultivar Oso grande apresentou maiores valores médios de número de frutos por planta $(9,5)$ em relação à cultivar Verão $(6,45)$. Esse maior desempenho para a cultivar Oso grande revela uma melhor adaptação às condiçôes climáticas desse estudo, caracterizadas por temperaturas máximas médias de $30,6{ }^{\circ} \mathrm{C}, 30,7^{\circ} \mathrm{C}, 30,8^{\circ} \mathrm{C}$ e $31,2{ }^{\circ} \mathrm{C}$, respectivamente do primeiro (abril) ao quarto mês de cultivo (agosto).

Outro fator que pode ter contribuído para esse maior desempenho da cultivar Oso grande ao longo do ciclo de cultivo pode estar relacionado à menor susceptibilidade dela ao abortamento de flores sob temperaturas elevadas. Em conformidade, para Andriolo et al. (2010), a menor produção

Tabela 4. Resumo da análise de variância para comprimento de fruto (CF), diâmetro de fruto (DC), número de frutos (NF), peso de fruto (PF) e produtividade do morangueiro (PROD)

\begin{tabular}{|c|c|c|c|c|c|c|}
\hline \multirow{2}{*}{ FV } & \multirow{2}{*}{ GL } & \multicolumn{5}{|c|}{ Quadrado médio } \\
\hline & & CF & DF & NF & PF & PROD \\
\hline Doses & 4 & $0,39^{\text {ns }}$ & $5,05^{\text {ns }}$ & $131,65^{* *}$ & $0,88^{\text {ns }}$ & $13,12^{* *}$ \\
\hline Variedades & 1 & $0,02^{\text {ns }}$ & $0,48^{\text {ns }}$ & $93,02^{*}$ & $0,09^{\text {ns }}$ & $4,81^{\text {ns }}$ \\
\hline DxV & 4 & $14,19^{\text {ns }}$ & $4,45^{\text {ns }}$ & $9,4^{\text {ns }}$ & $1,28^{*}$ & $4,19^{\text {ns }}$ \\
\hline Tratamentos & 9 & 10,48 & 4,28 & 73,02 & 0,97 & 8,23 \\
\hline Resíduo & 40 & 13,55 & 5,74 & 17,32 & 0,33 & 1,92 \\
\hline Total & 49 & - & - & - & - & - \\
\hline CV & - & 14,8 & 15,01 & 32,19 & 22,51 & 2,47 \\
\hline MG & - & 24,87 & 15,95 & 7,97 & 2,58 & 36,21 \\
\hline
\end{tabular}

$\mathrm{FV}=$ fonte de variação; $\mathrm{CV}=$ coeficiente de variação; $\mathrm{MG}=$ média geral; $\mathrm{GL}=$ grau de liberdade; ns = não significativo; ${ }^{*}$ significativo pelo teste $F$ a $5 \%$; ${ }^{*}$ significativo pelo teste $F$ a $1 \%$ 


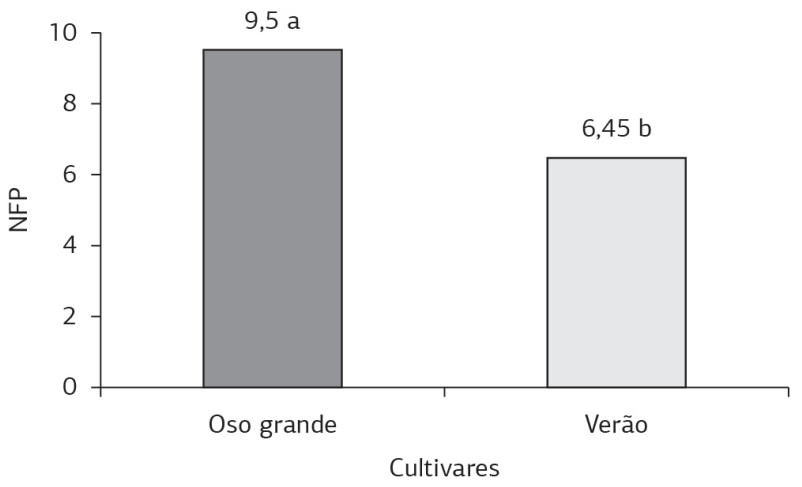

Figura 4. Número de frutos por planta do morangueiro em função das doses de potássio para as cultivares Oso grande e Verão.

de frutas pode ser atribuída ao abortamento de flores do morangueiro devido à ocorrência de elevadas temperaturas.

Oliveira et al. (2011), avaliando cultivares de morangueiro (Aromas; Camarosa e Ventana), constataram maior regularidade de produção, decorrente de floraçóes mais frequentes e uniformes, nos meses com temperaturas menores dentro do período de avaliação (agosto de 2007 a janeiro de 2008), nas condiçóes climáticas de Pelotas (RS).

$\mathrm{Na}$ figura 5 observa-se o efeito das diferentes doses de potássio sobre o número de frutos das cultivares Oso grande e Verão, e pela análise de regressão, constatou-se que o modelo estatístico que melhor se ajustou foi o linear decrescente.

O decréscimo do número de frutos com o aumento da concentração de potássio pode estar relacionado ao estresse salino constituído no substrato causado pelas doses elevadas do fertilizante potássico. Confirmando essa informação, Karlidag et al. (2009) descrevem que o morango é considerado uma espécie sensível à salinidade e é negativamente afetado por estresse salino em termos de crescimento e de produção.

Cabe ressaltar que a absorção desse nutriente não depende somente da sua disponibilidade em torno das raízes mas também da sua concentração (Andriolo et al., 2010) e do período de floração (Tagliavini et al., 2004).

Trabalhando nas condiçôes climáticas de Santa Maria, RS, Andriolo et al. (2010) verificaram um número de frutos superior ao deste estudo na variedade Arazá. Os autores encontraram valores entre 23 e 58 frutos por planta por um período de cinco meses após o início da colheita.

Analisando-se o efeito das doses de potássio sobre o peso de frutos, constatou-se, através da análise de regressão, que o modelo matemático que melhor se ajustou para as duas cultivares foram o linear (Verão) e o quadrático (Oso grande) (Figura 6).

A dose de potássio que proporcionou o maior peso de fruto para a cultivar Oso grande foi estimada em 2,6 g por planta. No entanto, a cultivar Verão apresentou maior peso de fruto $(2,94 \mathrm{~g})$ na dose $1,0 \mathrm{~g}$ por planta.

Esses resultados revelam que apesar de o K ser um nutriente considerado essencial para o crescimento e a qualidade de frutos dos vegetais (Prado, 2008), o excesso pode causar redução na

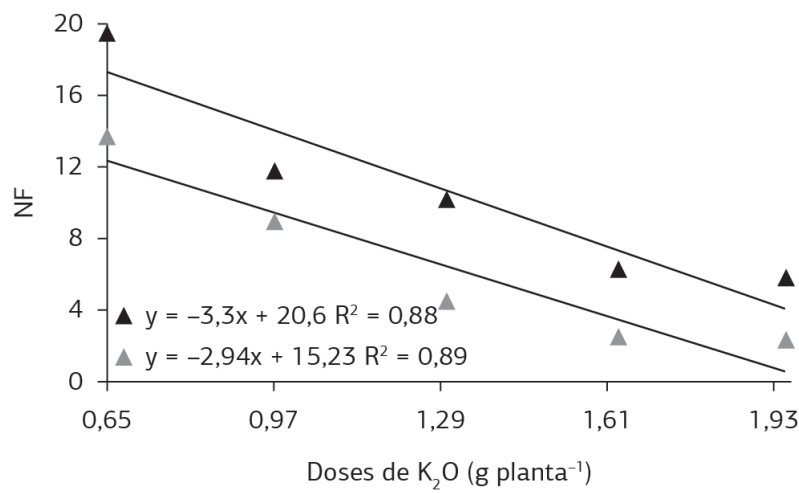

Figura 5. Número de frutos por planta do morangueiro em função das doses de potássio para as cultivares Oso grande $(\boldsymbol{\Lambda})$ e Verão ( $(\boldsymbol{\Lambda})$.

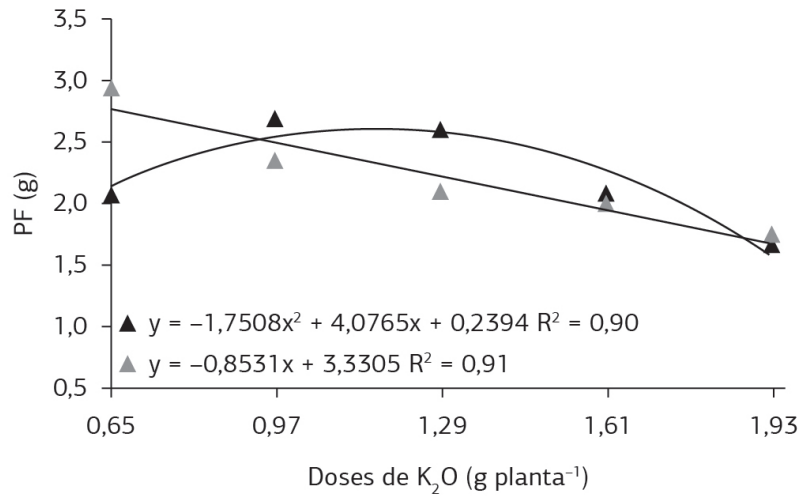

Figura 6. Peso de fruto de plantas do morangueiro em função das doses de potássio para as cultivares Oso grande $(\boldsymbol{\Lambda})$ e Verão $(\boldsymbol{\Lambda})$.

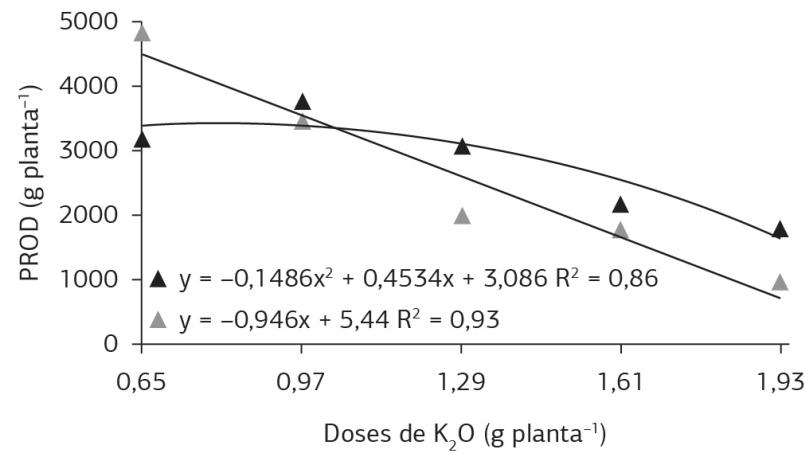

Figura 7. Produtividade de plantas do morangueiro em função das doses de potássio para as cultivares Oso grande $(\boldsymbol{\Lambda})$ e Verão $(\mathbf{\Lambda})$.

absorção de $\mathrm{Ca}$ e $\mathrm{Mg}$, chegando a causar a deficiência desses elementos (Albuquerque et al., 2011) e, consequentemente, menor peso de fruto. Andriolo et al. (2010) registraram resultados superiores ao deste estudo $(10,5 \mathrm{~g})$ ao avaliarem diferentes doses de potássio na cultivar Arazá em Santa Maria, RS. Esses autores encontraram peso de frutos por planta de $10,5 \mathrm{~g}$ na dose de $0,234 \mathrm{~g}$ de potássio. Provavelmente isso decorre das elevadas temperaturas do litoral cearense, o que reduz o ganho de fotoassimilados pela cultura.

Pela análise de regressáo para a produtividade do morangueiro para cultivares Oso grande e Verão (Figura 7) 
constatou-se efeito linear decrescente sob as diferentes doses de potássio.

Tendência semelhante foi obtida por Andriolo et al. (2010) que, ao avaliarem a produtividade da cultivar de morangueiro Arazá, constataram uma redução na produção com o aumento da concentraçáo de potássio aplicado via solução nutritiva.

Resultado oposto ao desse estudo foi verificado por Antunes et al. (2010), ao analisar a adubaçáo potássica na cultura do morangueiro cultivares Cama-rosa, Galexia, Earlibrite, Festival, Plarionfre e Sabrosa, nas condiçôes climáticas de Pelotas, RS. Esses autores concluíram que o excesso de potássio promove incremento na produçáo de frutos.

\section{CONCLUSÃO}

A adubação potássica estimula a produção de matéria seca da parte aérea e da matéria seca da raiz para as cultivares de morango Oso grande e Verão.

A dose de potássio $(0,65 \mathrm{~g}$ por planta) é mais eficiente para o número de frutos por planta para a cultivar Oso grande e para o peso médio de fruto para a Verão.

O aumento da concentração de potássio reduz a produtividade das cultivares de morango Oso e Verão.

A cultivar Oso grande apresenta maior adaptabilidade às condiçôes climáticas do litoral cearense do que a Verão.

\section{REFERÊNCIAS}

ALBUQUERQUE, F.C.; SILVA, E.F.F.; ALBUQUERQUE FILHO, J.A.C.; NUNES, M.F.F.N. Crescimento e rendimento de pimentão fertirrigado sob diferentes lâminas de irrigação e doses de potássio. Revista Brasileira de Engenharia Agrícola e Ambiental, v.15, p.686694, 2011.

ANDRIOLO, J.L.; JANISCH, D.I.; SCHMITT, O.J.; DAL PICIO, M.D.; CARDOSO, F.L.; ERPEN, L. Doses de potássio e cálcio no crescimento da planta, na produção e na qualidade de frutas do morangueiro em cultivo sem solo. Ciência Rural, v.40, p.267-272, 2010. http://dx.doi.org/10.1590/S0103-84782010000200003

ANDRIOLO, J.L.; JÄNISCH, D.I.; SCHMITT, O.J.; VAZ, M.A.B.; CARDOSO, F.L.; ERPEN, L. Concentração da soluçáo nutritiva no crescimento da planta, na produtividade e na qualidade de frutas do morangueiro. Ciência Rural, v.39, p.684-690, 2009. http://dx.doi. org/10.1590/S0103-84782009005000008

ANTUNES, L.E.C.; RISTOW, N.C.; KROLOW, A.C.R.; CARPENEDO, S.; REISSER JÚNIOR, C. Yield and quality of strawberry cultivars. Horticultura Brasileira, v.28, p.222-226, 2010. http://dx.doi.org/10.1590/S0102-05362010000200015

BARROSO, A.A.F.; VIANA, T.V.A.; MARINHO, A.B.; COSTA, S.C.; AZEVEDO, B.M. Teores de macronutrientes em folhas de bananeira cv. Pacovan apodi, sob lâminas de irrigação e doses de potássio. Engenharia Agrícola, v.31, p.529-538, 2011. http://dx.doi. org/10.1590/S0100-69162011000300013
CALVETE, E.O.; COSTA, R.C.; MENDONÇA, H.F.C.; BORDIGNOM JÚNIOR, C.L. Cultivo de morangueiro em ambiente protegido. In: FRUTICULTURA em ambiente protegido. Brasília: Embrapa, 2012. p.149-206.

CAMARGO, L.K.P.; RESENDE, J.T.V.; GALVÃO, A.G.; BAIER, J.E.; FARIA, M.V.; CAMARGO, C.K. Caracterização química de frutos de morangueiro cultivados em vasos sob sistemas de manejo orgânico e convencional. Semina, v.30, p.993-998, 2009.

EMPRESA BRASILEIRA DE PESQUisA AGROPECUÁRIA - EMBRAPA. Manual de métodos de análises de solo. 2.ed. Rio de Janeiro, 1997. 212p.

EPSTEIN, E.; BLOOM, A.J. Nutriçấo mineral de plantas. Londrina: Planta, 2006. 401p.

FRANCESCANGELI, N.; SANGIACOMO, M.A.; MARTI, $H$. Effects of plant density in broccoli on yield and radiation use efficiency. Scientia Horticulturae, v.110, p.135-143, 2006. http:// dx.doi.org/10.1016/j.scienta.2006.06.025

KARLIDAG, H.; YILDIRIM, E.; TURAN, M. Salicylic acid ameliorates the adverse effect of salt stress on strawberry. Scientia Agricola, v.66, p.180-187, 2009. http://dx.doi.org/10.1590/S010390162009000200006

MARQUES, D.J.; BROETTO, F.; SILVA, E.C.; CARVALHO J.G. Dinâmica de cátions na raiz e folhas de berinjela cultivada sobre doses crescentes de potássio oriundas de duas fontes. Idesia, v.29, p.69-77, 2011. http://dx.doi.org/10.4067/S0718-34292011000200009

MORALES, R.G.F.; FARIA, M.V.; RESENDE, J.T.V.; RISSINI, A.L.L.; RAFAELA, C.R.; FARIA, C.M.D.R. Produtividade do morangueiro em função da adubação orgânica complementar em cultivo protegido. Ambiência, v.8, p.23-33, 2012. http://dx.doi. org/10.5777/ambiencia.2012.01.02

OLIVEIRA, R.P.; NINO, A.F.P.; SCIVITTARO, W.B. Desempenho produtivo de mudas nacionais e importadas de morangueiro. Revista Brasileira de Fruticultura, v.28, p.520-522, 2006. http://dx.doi. org/10.1590/S0100-29452006000300040

OLIVEIRA, R.P.; NINO, A.F.P.; SCIVITTARO, W.B. Desempenho produtivo de cultivares de morangueiro. Scientia Agrária, v.12, p.6974. 2011

PACHECO, D.D.; DIAS, M.S.C.; ANTUNES, P.D.; RIBEIRO, D.P.; SILVA, J.J.C.; PINHO, D.B. Nutrição mineral e adubação do morangueiro. Informe Agropecuário, v.28, p.40-49, 2007.

PADOVANI, M.I. Morango: o delicado e saboroso fruto da integraçáo dos povos. São Paulo: Ícone, 1991. 68p.

PRADO, R.M. Nutrição de plantas. São Paulo: UNESP, 2008. 408p.

RAIJ, B.; CANTARELLA, H.; QUAGGIO, J.A.; FURLANI, A.M.C. Recomendações de adubação e calagem para o Estado de São Paulo. Campinas: IAC, 1996. 285p. (Boletim técnico, n.100)

TAGLIAVINI, M.; BALDI, E.; NESTBY, R.; RAYNAL-LACROIX, C.; LIETEN, P.; SALO, T.; PIVOT, D.; LUCCHI, P.L.; BARUZZI, G.; FAEDI, W. Uptake and partitioning of major nutrients by strawberry plants. Acta Horticulturae, v.649, p.197-200, 2004.

TAIZ, L.; ZEIGER, E. Fisiologia vegetal. 4.ed. Porto Alegre: Artmed, 2009. 729p. 